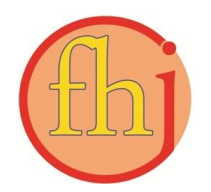

Faletehan Health Journal, 6 (3) (2019) 118-124

www. journal.Ippm-stikesfa.ac.id/ojs/index.php/FHJ

ISSN 2088-673X | e-ISSN 2597-8667

\title{
Determinan Perilaku Hidup Bersih dan Sehat Pada Siswa Sekolah Dasar Negeri
}

\author{
Titin Nasiatin ${ }^{1 *}$, Irma Nurul Hadi ${ }^{1}$ \\ ${ }^{1}$ Program Studi Kesehatan Masyarakat, Fakultas IImu Kesehatan, Universitas Faletehan \\ *Corresponding Author: ti2n.nasiatin@gmail.com
}

\begin{abstract}
Abstrak
Perilaku Hidup Bersih dan Sehat di sekolah adalah upaya untuk memberdayakan siswa, guru, dan masyarakat lingkungan sekolah agar tahu, mau dan mampu menolong diri sendiri di bidang kesehatan dengan menerapkan PHBS dan berperan aktif dalam mewujudkan sekolah sehat. Tujuan pada penelitian ini untuk mengetahui determinan PHBS pada siswa SDN di Kelurahan Deringo Kecamatan Citangkil Kota Cilegon Tahun 2019. Desain penelitian bersifat cross sectional. Sampel penelitian ini sebanyak 107 siswa kelas 5, yang diambil menggunakan metode total sampling. Pengumpulan data primer menggunakan kuesioner, sedangkan data sekunder didapat dari Puskesmas Citangkil dan sekolah. Berdasarkan hasil penelitian diketahui sebanyak 49,5\% siswa mempunyai PHBS kurang baik, 36,4\% pengetahuan kurang baik, 44,9\% menunjukkan sikap negatif, $42,1 \%$ siswa menyatakan peran guru kurang baik dan $43,9 \%$ siswa menyatakan peran orang tua kurang baik. Uji statistik menunjukkan terdapat hubungan yang bermakna antara sikap $(p=0,009)$, peran guru $(p=\varangle, 001)$ dan peran orang tua $(p=0,001)$ dengan PHBS pada siswa SD. Saran dari penelitian ini diharapkan pihak sekolah dapat memaksimalkan fungsi UKS dan dapat menyediakan sarana dan prasarana yang mendukung PHBS siswa. Kata Kunci: PHBS, Peran guru, Peran Orang tua, Sikap
\end{abstract}

\begin{abstract}
Clean Life And Healthy Behavior (CLHB) in schools is an effort to empower students, teachers, and community in the school environment to know, want and be able to help themselves in the field of health by implementing CLHB and play an active role in realizing healthy schools. The purpose of this research was to know the determinant to CLHB in elementary school students in Deringo Village Citangkil District Cilegon City Year 2019. Research design is cross sectional. The sample of this research is 107 students of grade 5, where taken using total sampling method. Primary data collection using questionnaires. Secondary data obtained from Citangkil Puskesmas and school. Based on research results obtained as much as $49.5 \%$ of students who perform CLHB less, $36,4 \%$ have poor knowledge, $44.9 \%$ have a negative attitude, 42 , $1 \%$ of students said that the teacher support were less and $43,9 \%$ parents support were less. The results of analysis showed that there was a significant relationship between attitudes $(p v=0.009)$, the teachers support $(p v=0,000)$ and the parents support $(p v=0,000)$ with CLHB in elementary school students. Suggestions from this research are expected that the school can maximize the function of UKS and provide facilities and infrastructures that support CLHB of students. Keywords: CLHB, Attitude, Parents support, Teacher's support
\end{abstract}


Faletehan Health Journal, 6 (3) (2019) 118-124

\section{Pendahuluan}

Organisasi Kesehatan Dunia (WHO) telah mencanangkan konsep sekolah sehat (Health Promoting School) atau sekolah yang mempromosikan kesehatan dengan menggunakan model holistik yang meliputi keterkaitan antara aspek fisik, mental, sosial dan lingkungan kesehatan. Konsep ini melibatkan keluarga dengan mendorong partisipasi mereka dalam pengembangan keterampilan kesehatan dan pengetahuan peserta didik (mulai dari usia dini) tentang kesehatan serta menunjukkan makna lingkungan sebagai penyumbang kesehatan anak seperti kondisi fisik sekolah, sanitasi air bersih, dan lingkungan bermain.

Konsep sekolah sehat tersebut tentunya ditujukan untuk meningkatkan kualitas sumber daya manusia. Dimana kualitas sumber daya manusia (SDM) sangat dipengaruhi oleh dua faktor yang saling berhubungan dan berkaitan yaitu pendidikan dan kesehatan. Upaya untuk meningkatkan kualitas sumber daya manusia melalui pendidikan dan kesehatan tentunya harus dimulai sejak dini baik pada masa prasekolah maupun masa sekolah. Anak usia sekolah termasuk kelompok masyarakat yang mempunyai resiko tinggi dan waktu yang paling tepat untuk menanamkan pengertian dan kebiasaan hidup sehat. Anak usia sekolah merupakan kelompok yang paling rentan terhadap penyakit, oleh karena itu pendidikan kesehatan bagi mereka menjadi hal yang perlu mendapatkan perhatian utama. Banyak data menyebutkan bahwa munculnya berbagai penyakit yang sering menyerang anak usia sekolah yang salah satunya adalah diare umumnya berkaitan dengan Perilaku Hidup Bersih dan Sehat (PHBS) (Maryuani, 2013).

Diare merupakan salah satu penyakit berbasis lingkungan yang dapat disebabkan karena perilaku hidup bersih dan sehat yang rendah. Badan Kesehatan Dunia atau World Health Organization (WHO) mencatat bahwa setiap tahun terdapat 100.000 anak di Indonesia meninggal di sebabkan diare. Berdasarkan data Profil Kesehatan Indonesia Tahun 2017 mencatat bahwa penderita diare semua umur yang dilayani di sarana kesehatan tahun 2016 sebanyak 3.176.079 penderita dan terjadi peningkatan pada tahun 2017 yaitu menjadi 4.274.790 penderita atau $60,4 \%$ dari perkiraan diare di sarana kesehatan. Insiden diare semua umur secara nasional adalah 270/1.000 penduduk (Kemenkes, 2017).
PHBS merupakan sekumpulan perilaku yang dipraktikkan atas dasar kesadaran individu untuk mencegah permasalahan kesehatan. PHBS dipraktikkan atas kesadaran sebagai hasil pembelajaran, yang menjadikan seseorang atau keluarga dapat menolong diri sendiri di bidang kesehatan dan berperan aktif dalam mewujudkan kesehatan masyarakatnya. Kebijakan PHBS menjadi komponen penting suatu daerah sebagai indikator suatu keberhasilan daerah untuk menurunkan kejadian penyakit yang disebabkan oleh perilaku yang tidak sehat (Kemenkes, 2017). Data menunjukkan bahwa presentase Kabupaten/Kota yang memiliki kebijakan PHBS secara nasional pada tahun 2017 sebesar 60,89\% dan angka ini sudah mencapai target Renstra 2017 $60 \%$. Sebanyak 9 provinsi sudah mencapai target 100\% yaitu Sulawesi Barat, Gorontalo, Bali, DI Yogyakarta, Jawa Tengah, DKI Jakarta, Kepulauan Riau dan Bengkulu. Provinsi dengan presentase terendah adalah Papua 3,45\%, Papua Barat 15,38\% dan Nusa Tenggara Timur 18,18\% (Kemenkes, 2017).

Hasil PHBS berdasarkan Riset Kesehatan Dasar tahun 2013 menunjukkan bahwa 95,7\% anak sudah menyikat gigi setiap harinya, namun hanya $1,7 \%$ saja yang telah melakukannya dengan benar. Selain itu, perilaku konsumsi tembakau aktif setiap hari pada anak mencapai $0,5 \%$ dan $0,9 \%$ lainnya merokok dengan intensitas kadang-kadang. Berdasarkan analisis kecenderungan secara rerata nasional, sebanyak $82,6 \%$ penduduk telah melakukan $\mathrm{BAB}$ dengan benar, yaitu di jamban. Hanya $47 \%$ penduduk Indonesia yang telah melakukan cuci tangan dengan benar. Sebanyak $26,1 \%$ penduduk di Indonesia masuk dalam kategori kurang aktif dalam beraktivitas (Riskesdas, 2013). Angka PHBS dari tahun 2005 sampai 2015 menunjukkan kenaikan. Mulai dari $27 \%$ meningkat menjadi 36,3\% di tahun 2013 dan $40 \%$ di tahun 2015. Sementara itu target nasional tahun 2019 diharapkan penduduk Indonesia yang memenuhi kriteria PHBS baik dapat mencapai angka 80\% (Kemenkes, 2014).

Data Riskesda Provinsi Banten tahun 2013 menyebutkan bahwa dari 8 kabupaten/kota seProvinsi Banten diketahui bahwa proporsi penduduk yang memenuhi kriteria PHBS yang paling rendah terdapat di Kabupaten Lebak $(12,7 \%)$, disusul oleh Kabupaten Pandeglang (14,7\%), Kabupaten Serang (20,8\%), Kota Serang $(30,1 \%)$, Kabupaten Tangerang (35,9\%), Kota 
Cilegon $(37,1 \%)$ dan Kota Tangerang $(47,4 \%)$. Sedangkan cakupan PHBS paling tinggi terdapat di Kota Tangerang Selatan sebesar 56,1\% (Riskesdas Propinsi Banten, 2013). Kecamatan Citangkil merupakan salah satu wilayah di Kota Cilegon yang menduduki peringkat pertama dengan cakupan 44\% tidak ber PHBS pada tahun 2017. Kecamatan Citangkil juga menduduki peringkat pertama kejadian diare pada tahun 2018 di Kota Cilegon yang mencapai 2.843 kasus (Riskesdas Propinsi Banten, 2013).

Penerapan PHBS di sekolah dapat dipengaruhi oleh banyak faktor, diantaranya adalah pengetahuan siswa, sikap, peran guru, peran orang tua, keterpaparan media, ketersediaan sarana prasarana dan faktor lainnya. Hal ini didukung oleh berbagai penelitian yang menyebutkan bahwa PHBS di sekolah berhubungan dengan variabelvariabel tersebut. Hasil penelitian Lina menyebutkan bahwa siswa SD mempunyai tingkat pengetahuan yang rendah tentang penggunaan jamban bersih dan sehat $(67,6 \%)$ serta sebanyak $56,3 \%$ responden tidak menerima untuk jajan sehat di kantin sekolah (Lina, 2016). Penelitian lainnya juga menyebutkan bahwa sebagian besar $(54,7 \%)$ siswa SD belum melakukan perilaku hidup bersih dan sehat, sementara guru yang diharapkan menjadi sosok teladan dalam berperilaku hidup bersih dan sehat belum menunjukkan peran yang maksimal dalam PHBS siswa. Penelitian yang sama juga menunjukkan terdapat hubungan antara pengetahuan dengan pelaksanaan program PHBS pada siswa (Diana, 2014). Penelitian Kusuma, Pertiwi dan Annissa menyebutkan bahwa sebanyak 68\% siswa SD mempunyai Perilaku Hidup Bersih Dan Sehat (PHBS) yang baik dan sebanyak 68,7\% mempunyai tingkat pengetahuan baik (Kusuma, Pertiwi dan Annissa, 2019). Orang tua juga mempunyai peran dalam mendorong anak-anak untuk berperilaku hidup bersih dan sehat. Hal ini didukung oleh penelitian yang menyebutkan bahwa terdapat hubungan yang signifikan antara pengetahuan dan peran orang tua dengan perilaku hidup bersih dan sehat (nilai $\mathrm{p}=0,003$ dan 0,001 ) (Wulandari, Pertiwi, 2019).

Penelitian ini bertujuan untuk mengetahui determinan PHBS pada Siswa SDN Di Kelurahan Deringo, Cilegon tahun 2019.

\section{Metode Penelitian}

Desain penelitian yang digunakan dalam penelitian ini menggunakan pendekatan cross sectional. Penelitian dilaksanakan di SDN yang terdapat di Kelurahan Deringo Kecamatan Citangkil Kota Cilegon pada bulan Maret-Mei 2019. Variabel independen yang diteliti yaitu pengetahuan, sikap, peran guru dan peran orang tua dan variabel dependen yaitu PHBS pada siswa SD. Populasi dalam penelitian ini adalah seluruh siswa/siswi SDN kelas 5 dan sampel dalam penelitian adalah total populasi dengan teknik pengambilan sampel secara total sampling sebanyak 107 siswa. Penelitian ini menggunakan data primer yang diperoleh secara langsung dari responden dengan menggunakan alat ukur kuesioner. Analisa data dilakukan secara univariat dan bivariat menggunakan Uji Kai Kuadrat (Chi Square test).

\section{Hasil dan Pembahasan}

Dari hasil penelitian yang dianalisis secara univariat, pada tabel 1 sebanyak 50,5\% siswa yang melakukan PHBS baik, sebanyak 63,6\% siswa mempunyai pengetahuan yang baik, sebanyak $55,1 \%$ siswa mempunyai sikap yang positif, sebanyak $57,9 \%$ siswa menyatakan peran guru yang baik dan siswa yang menyatakan peran orang tua yang baik sebanyak $56,1 \%$. Berdasarkan tabel 2 menunjukkan terdapat hubungan antara sikap, peran guru dan peran orang tua dengan PHBS, dan tidak ada hubungan antara pengetahuan dengan PHBS.

Tabel 1. Distribusi Frekuensi Determinan PHBS pada Siswa $(n=107)$

\begin{tabular}{lcc}
\hline \multicolumn{1}{c}{ Variabel } & n & \% \\
\hline PHBS & & \\
$\quad$ Kurang Baik & 53 & 49.5 \\
$\quad$ Baik & 54 & 50.5 \\
\hline Pengetahuan & 39 & 36.4 \\
$\quad$ Kurang Baik & 68 & 63.6 \\
$\quad$ Baik & & \\
\hline Sikap & 48 & 44.9 \\
$\quad$ Negatif & 59 & 55.1 \\
$\quad$ Positif & & \\
\hline Peran Guru & 45 & 42.1 \\
$\quad$ Kurang Baik & 62 & 57.9 \\
$\quad$ Baik & & \\
\hline Peran Orang Tua & 47 & 43.9 \\
$\quad$ Kurang Baik & 60 & 56.1 \\
$\quad$ Baik & 107 & 100 \\
\hline Jumlah &
\end{tabular}


Faletehan Health Journal, 6 (3) (2019) 118-124 www. journal.Ippm-stikesfa.ac.id/ojs/index.php/FHJ ISSN 2088-673X | e-ISSN 2597-8667

\section{Perilaku Hidup Bersih dan Sehat}

Perilaku hidup bersih dan sehat merupakan sekumpulan perilaku yang dipraktikkan atas dasar kesadaran individu untuk mencegah permasalahan kesehatan. PHBS sebagai hasil pembelajaran yang menjadikan seseorang atau keluarga dapat menolong diri sendiri di bidang kesehatan dan berperan aktif dalam mewujudkan kesehatan masyarakat. Penerapan PHBS pada tatanan sekolah sangat dipengaruhi oleh banyak hal. Secara umum, PHBS merupakan perilaku yang menurut teori Lawrence Green dipengaruhi oleh 3 faktor utama yaitu faktor predisposisi, faktor enabling dan faktor reinforcing (Green, 1980). Pada penelitian ini, faktor terbentuknya perilaku dilihat dari faktor predisposisi berupa pengetahuan dan sikap, serta faktor reinforcing yang berupa dukungan/peran orang tua dan guru.

Berdasarkan hasil penelitian diketahui bahwa proporsi antara responden yang berPHBS baik hampir sama dengan yang berPHBS kurang baik. Sebanyak 50,5\% responden menunjukkan perilaku hidup bersih dan sehat yang baik. Hal ini sesuai dengan hasil penelitian sebelumnya yang menyebutkan bahwa proporsi siswa SD kelas V yang mempunyai Perilaku Hidup Bersih dan Sehat pada kategori baik lebih banyak, yaitu sebesar $68 \%$ (Kusuma, Pertiwi, Annissa, 2019). Hasil penelitian juga sejalan dengan penelitian lainnya yang menunjukkan bahwa kondisi PHBS siswa SD di Kecamatan Kramatwatu berada pada kondisi baik (55.2\%), kurang baik sebanyak $44.8 \%$ (Rahayu, Pertiwi, Nurdiawati, 21013).

Seperti diketahui bahwa indikator PHBS di sekolah terdiri dari perilaku mencuci tangan dengan air yang mengalir dan menggunakan sabun, mengkonsumsi jajanan sehat di kantin sekolah, menggunakan jamban yang bersih dan sehat, olahraga yang teratur dan terukur, memberantas jentik nyamuk, tidak merokok di sekolah, menimbang berat badan dan mengukur tinggi badan setiap 6 bulan serta membuang sampah pada tempatnya. Berdasarkan hasil penelitian, PHBS yang kurang baik meliputi perilaku mencuci tangan dengan air mengalir dan sabun, mengkonsumsi jajanan sehat di kantin sekolah. Pada umumnya responden mencuci tangan dengan air mengalir saja dan membeli jajanan diluar kantin sekolah, karena memang di sekolah tidak disediakan kantin sehat. Kebutuhan makanan/jajanan anak sekolah disediakan oleh para pedagang asongan yang seringkali mangkal di sekitar sekolah.

Tabel 2. Hubungan Antar Variabel Penelitian ( $\mathrm{n}=107)$

\begin{tabular}{|c|c|c|c|c|c|c|}
\hline \multirow{3}{*}{ Variabel } & \multicolumn{4}{|c|}{ PHBS } & \multirow{3}{*}{ Jumlah } & \multirow{3}{*}{ pvalue } \\
\hline & \multicolumn{2}{|c|}{ Kurang Baik } & \multicolumn{2}{|c|}{ Baik } & & \\
\hline & $\mathbf{n}$ & $\%$ & $\mathbf{n}$ & $\%$ & & \\
\hline \multicolumn{7}{|l|}{ Pengetahuan } \\
\hline Kurang Baik & 21 & 53,8 & 18 & 46,2 & 39 & 0,635 \\
\hline Baik & 32 & 47,1 & 36 & 52,9 & 68 & \\
\hline \multicolumn{7}{|l|}{ Sikap } \\
\hline Negatif & 31 & 64,6 & 17 & 35,4 & 48 & 0,009 \\
\hline Positif & 22 & 37,3 & 37 & 62,7 & 59 & \\
\hline \multicolumn{7}{|l|}{ Peran Guru } \\
\hline Kurang Baik & 34 & 75,6 & 11 & 24,4 & 45 & 0,000 \\
\hline Baik & 19 & 30,6 & 43 & 69,4 & 62 & \\
\hline \multicolumn{7}{|l|}{ Peran Orang Tua } \\
\hline Kurang Baik & 36 & 76,6 & 11 & 23,4 & 47 & 0,000 \\
\hline Baik & 17 & 28,3 & 43 & 71,7 & 60 & \\
\hline Jumlah & 53 & 49,5 & 54 & 50,5 & 107 & \\
\hline
\end{tabular}




\section{Pengetahuan siswa tentang PHBS}

Pengetahuan atau kognitif merupakan domain yang sangat penting untuk terbentuknya tindakan seseorang (overt behavior) karena dari pengalaman dan penelitian ternyata perilaku yang didasari oleh pengetahuan lebih langgeng daripada perilaku yang tidak didasari oleh pengetahuan (Notoadmodjo, 2012). Berdasarkan hasil penelitian menunjukkan tidak ada hubungan yang signifikan antara pengetahuan dengan perilaku hidup bersih dan sehat (PHBS) pada siswa SDN di Kelurahan Deringo Kecamatan Citangkil Kota Cilegon. Hasil penelitian ini sejalan dengan penelitian sebelumnya yang menyatakan tidak terdapat hubungan yang bermakna antara pengetahuan dengan PHBS pada siswa sekolah dasar (Kanro, 2017; Kusuma, Pertiwi, Annissa, 2019). Hasil penelitian tidak sejalan dengan penelitian sebelumnya yang menyebutkan bahwa terdapat hubungan yang signifikan antara pengetahuan dengan PHBS siswa SD. Siswa dengan tingkat pengetahuan kurang baik tentang PHBS mempunyai persentase yang lebih banyak $(56,3 \%)$ dibandingkan dengan siswa yang berpengetahuan baik (Wulandari, Pertiwi, 2018).

PHBS dipengaruhi oleh banyak hal, bukan hanya pengetahuan saja melainkan juga dipengaruhi oleh peran guru, peran orang tua, motivasi siswa, peran peergroup, ketersediaan sarana-prasarana PHBS di sekolah serta kebijakan dan dukungan dari sekolah atau lembaga terkait lainnya. Pengetahuan siswa tentang PHBS dapat terus ditingkatkan melalui berbagai upaya, misalnya dengan memberikan penyuluhan/pendidikan kesehatan secara berkala kepada siswa, menyediakan media-media promosi kesehatan. Penyuluhan/pendidikan kesehatan secara signifikan berhubungan dengan pengetahuan dan sikap siswa sebelum dan sesudah diberikan intervensi penyuluhan kesehatan. Siswa yang telah diberikan intervensi penyuluhan menunjukkan peningkatan pengetahuan (Presska, Salawati, \& Astuti, Agustus 2012). Hasil penelitian menunjukkan bahwa persentase siswa yang berpengetahuan baik lebih banyak (68\%) dibandingkan siswa yang berpengetahuan kurang baik. Penelitian ini juga diketahui bahwa proporsi siswa yang berPHBS baik dan mempunyai tingkat pengetahuan baik lebih banyak dibanding yang berPHBS kurang baik dengan tingkat pengetahuan yang baik.

\section{Sikap siswa terhadap PHBS}

Sikap merupakan reaksi atau respon tertutup dari seseorang terhadap suatu stimulus atau objek yang sudah melibatkan faktor pendapat dan emosi yang bersangkutan (senang-tidak senang, setujutidak setuju, baik-tidak baik, dan sebagainya). Newcomb, salah seorang ahli psikologi sosial menyatakan bahwa sikap merupakan kesiapan atau kesediaan untuk bertindak dan bukan merupakan pelaksanaan motif tertentu. Dalam kata lain, fungsi sikap belum merupakan tindakan (reaksi terbuka) atau aktivitas, akan tetapi merupakan predisposisi perilaku tindakan atau reaksi tertutup (Notoadmodjo, 2012). Berdasarkan hasil penelitian diketahui bahwa terdapat hubungan yang signifikan antara sikap dengan perilaku hidup bersih dan sehat (PHBS) pada siswa SDN di Kelurahan Deringo Kecamatan Citangkil Kota Cilegon. Hasil penelitian ini sejalan dengan penelitian yang dilakukan oleh Suryani (2017), yang menyatakan ada hubungan antara sikap dengan perilaku hidup bersih dan sehat (PHBS) di SDN 37 Kota Pekanbaru (Suryani, 2017; Kwureh, 2016).

Berdasarkan hasil di lapangan, ada hubungan yang bermakna antara sikap dengan PHBS, hal ini dikarenakan siswa telah memiliki sikap yang positif terhadap pelaksanaan PHBS di sekolah. Untuk mewujudkan sikap menjadi suatu perbuatan nyata diperlukan faktor pendukung seperti fasilitas atau sarana prasarana yang berkaitan dengan PHBS seperti tempat cuci tangan beserta sabun, tempat sampah, kantin sehat dan lain sebagainya. Sikap positif responden belum didukung oleh perilaku hidup bersih dan sehat yang baik. Hal ini terlihat pada masih banyaknya siswa yang tidak melakukan PHBS secara baik dan benar, seperti mencuci tangan dengan air mengalir saja tetapi tidak menggunakan sabun, tidak tersedianya kantin sehat membuat siswa jajan di luar lingkungan sekolah. Sikap tentang PHBS yang baik merupakan salah satu faktor yang dapat mendorong seseorang untuk berperilaku hidup bersih dan sehat.

\section{Peran Guru terhadap PHBS}

Guru merupakan unsur yang sangat penting dalam pelaksanaan promosi kesehatan di dalam merubah perilaku muridnya. Guru yang mendukung penerapan perilaku hidup bersih dan sehat akan membuat siswa melakukan perilaku hidup bersih dan sehat di sekolah karena guru 
Faletehan Health Journal, 6 (3) (2019) 118-124

www. journal.Ippm-stikesfa.ac.id/ojs/index.php/FHJ

ISSN 2088-673X | e-ISSN 2597-8667

merupakan orang tua kedua bagi anak di sekolah dan orang yang paling tahu bagaimana anak disekolah dibandingkan orang tuanya (Notoadmodjo, 2012). Pada penelitian ini, peran guru terbukti secara signifikan berhubungan dengan dengan perilaku hidup bersih dan sehat (PHBS) pada siswa SDN. Hasil penelitian ini sejalan dengan penelitian yang dilakukan oleh Selviana (2018), yang menyatakan ada hubungan yang bermakna antara peran guru dengan perilaku hidup bersih dan sehat (PHBS) pada siswa SD Muhammadiyah 1 dan 3 Kota Pontianak (Selviana, Suwarni, Ruhama, 2018; Latifah\&Rindu, 2014).

Di Sekolah, guru merupakan sosok yang diteladani oleh siswa, sehingga salah satu faktor pendorong PHBS yang baik pada siswa adalah guru. Hal ini dikarenakan guru menjadi contoh kepada muridnya berperilaku hidup bersih dan sehat di sekolah. Selain memberikan contoh guru juga berperan untuk mengawasi dan mengontrol siswa dalam menerapkan perilaku hidup bersih dan sehat di sekolah.

\section{Peran Orang Tua terhadap PHBS}

Orang tua mempunyai peran penting dalam mendorong anak untuk berperilaku hidup bersih dan sehat. Orang tua merupakan figur yang paling dekat dan paling mengetahui perkembangan perilaku hidup anaknya, karena anak-anak menghabiskan waktunya di rumah bersama orang tua dan keluarga lainnya. Orangtua merupakan contoh bagi anaknya di rumah sehingga orang tua sangat berperan dalam perilaku hidup bersih dan sehat siswa karena orangtua merupakan orang terdekat dengan anak, perilaku dan perbuatan orang tua merupakan contoh bagi anak. Berdasarkan hasil penelitian menunjukkan bahwa terdapat hubungan yang signifikan antara peran orang tua dengan perilaku hidup bersih dan sehat (PHBS) pada siswa. Hasil penelitian ini sejalan dengan penelitian sebelumnya, yang menyatakan ada hubungan yang antara peran orang tua dengan perilaku hidup bersih dan (Berliana, Pradana, 2016; Latifah, 2014; Wulandari, Pertiwi, 2018). (Berliana \& Pradana, 2016)

Berdasarkan hasil di lapangan, peran orang tua baik dikarenakan orang tua memiliki tugas untuk mengajarkan, menyediakan fasilitas atau sarana seperti tempat cuci tangan beserta sabunnya, tempat sampah, jamban sehat dan lain sebagainya dan membiasakan untuk berperilaku hidup bersih dan sehat di rumah dengan cara memberikan contoh yang baik pada anak terkait dengan PHBS. Pemahaman PHBS di sekolah yang diberikan oleh guru juga akan dipraktekkan/dilaksanakan oleh siswa di rumah. Ketika di rumah itulah kemudian orang tua menjadi kunci dalam penerapan dan penguatan PHBS siswa. Perilaku-perilaku hidup bersih seperti menggosok gigi $2 \mathrm{x}$ sehari, melakukan $\mathrm{BAB} / \mathrm{BAK}$ di jamban/WC, membuang sampah pada tempatnya, sebelum makan harus cuci tangan pakai sabun harus terus ditanamkan baik di sekolah maupun di rumah sehingga anak dengan sendirinya akan terbiasa untuk melakukan dan menjadi sebuah kebiasaan yang baik.

\section{Simpulan}

Berdasarkan hasil penelitian disimpulkan bahwa sikap, peran guru dan peran orang tua berhubungan secara signifikan dengan PHBS pada siswa. Siswa SD yang memiliki PHBS kategori baik sedikit lebih banyak dibanding siswa yang berPHBS kurang baik.

\section{Referensi}

Adiwiryono, R. (2010). Pesan Kesehatan: Perilaku Hidup Bersih dan Sehat (PHBS) Anak Usia Dini dalam Kurikulum Pendidikan Anak Usia Dini. Jurnal Ilmu Kesehatan Universitas Muhammadiyah Prof.Hamka.

Berliana, N., \& Pradana, E. (2016). Hubungan Peran Orang Tua, Pengaruh Teman Sebaya dengan Perilaku Hidup Bersih dan Sehat. Journal Endurance June 2016, 75-80.

Depkes RI. (2011). Pedoman Pembinaan Perilaku Hidup Bersih dan Sehat (PHBS). Jakarta: Depkes RI.

Depkes RI. (2012). Pembinaan Perilaku Hidup Bersih dan Sehat di Berbagai Tatanan. Jakarta: Pusat Promosi Kesehatan.

Dinkes Cilegon. (2018). Profil Kesehatan Kota Cilegon Tahun 2018. Cilegon: Dinas Kesehatan Kota Cilegon.

Evayanti. (2012). Persepsi Siswa SMP Dalam Penerapan PHBS Tatanan Sekolah Dikelurahan Tugu dan Pasir Gunung Selatan Kota Depok. \{Thesis\}. Depok: FIK Universitas Indonesia.

Kanro, R., Yasnani, \& Saptaputra, k. S. (2016). Faktor-faktor yang Berhubungan dengan Perilaku Hidup Bersih dan Sehat Pada Anak Usia Sekolah Dasar Negeri 08 Moramo Utara Desa Wawatu Kecamatan Moramo Utara Kabupaten Konawe Selatan Tahun 2016. 
Jurnal Ilmiah Mahasiswa Kesehatan Masyarakat, Vol.2/No.6/Mei 2017.

Kemenkes RI. (2014). Profil Kesehatan Indonesia Tahun 2014. Jakarta:

Kemenkes RI. (2017). Profil Kesehatan Indonesia Tahun 2017. Jakarta: Kemenkes RI.

Kusuma, A. N. Pertiwi, W. E. (2019). The Relationship Between Healthy Media Promotion, Knowledge with the Clean and Healthy Life Behavior of Elementary Students. Laporan Penelitian. Serang: Lembaga Penelitian dan Pengabdian Kepada Masyarakat.

Kwureh, N. H. (2016). Hubungan Jenis Kelamin, Pengetahuan, Sikap dan Peran Guru dengan Perilaku Hidup Bersih dan Sehat Pada Siswa SD Negeri 25 Begori Kecamatan Serawai Kabupaten Sintang. Program Studi Kesehatan Masyarakat Sekolah Tinggi Ilmu Kesehatan Kapuas Raya Sintang.

Latifah, N. R., \& Rindu. (2014). Perilaku Hidup Bersih dan Sehat (PHBS) Pada Anak SD Di Kota Bekasi 2014. Jurnal Ilmiah Kesehatan Vol. 6 (2); Juli 2014.

Notoatmodjo, S. (2010). Promosi Kesehatan dan Ilmu Perilaku. Jakarta: Rineka Cipta.

----. (2011). Kesehatan Masyarakat Ilmu dan Seni. Jakarta: Rineka Cipta.

----. (2012). Promosi Kesehatan dan Perilaku Kesehatan. Jakarta: Rineka Cipta.

Purwatih, E. (2016). Analisis Faktor-Faktor Yang Berhubungan Dengan Perilaku Hidup Bersih Dan Sehat (PHBS) Pada Siswa SDN Cinangka Kelurahan Cinangka Kabupaten Serang
Tahun 2016. Skripsi: STIKes Faletehan Serang.

Puskesmas Citangkil. (2018). Program Diare.

Wulandari, R, D. Pertiwi, W,E. (2018). Hubungan Antara Pengetahuan Dan Peran Orang Tua Dengan Perilaku Hidup Bersih Dan Sehat Pada Siswa Sekolah Dasar di SD Margasana Kecamatan Kramatwatu Tahun 2018. Jurnal Dunia KesMas. Vol.7, No.4, p: 225-232

Riskesdas. (2013). Riset Kesehatan Dasar. Jakarta: Badan Penelitian dan Pengembangan Kesehatan Kementerian Kesehatan RI.

(2013). Riset Kesehatan Dasar: Provinsi Banten 2013. Jakarta: Badan Penelitian dan Pengembangan Kesehatan Kementerian Kesehatan RI.

Selviana, Putra, G. S., Suwarni, L., \& Ruhama, U. (2018). Determinan Perilaku Hidup Bersih dan Sehat Pada Siswa SD Muhammadiyah 1 dan 3 di Kota Pontianak. Jurnal Publikasi Kesehatan Masyarakat Indonesia, Vol.5 No.2, Agustus 2018.

Suryani, L. (2017). Faktor-Faktor Yang Mempengaruhi Perilaku Hidup Bersih Dan Sehat (PHBSP Siswa/i Sekolah Dasar Negeri 37 Kecamatan Tampan Kota Pekanbaru. STIKes Payung Negeri Pekanbaru.

Syahputri, D. (2011). Hubungan Pengetahuan dan Sikap Siswa Sekolah Dasar (SD) tentang Sanitasi Dasar Dengan Perilaku Hidup Bersih dan Sehat (PHBS) di Kelurahan Harjosari 1 Kecamatan Medan Amplas. Fakultas Kesehatan Masyarakat, Universitas Sumatera Utara. 